Uma reconstrução racional do racionalismo neoclássico

\title{
UMA RECONSTRUÇÃO RACIONAL DO PROGRAMA DE PESQUISA DO RACIONALISMO NEOCLÁSSICO: OS SUBPROGRAMAS DO CONVENCIONALISMO/ pragmatismo (Poincaré) e do Realismo ESTRutural CONVERGENTE (DUHEM)
}

\author{
José Raimundo Novaes Chiappin ${ }^{1}$ \\ Ana Carolina Leister ${ }^{2}$
}

RESUMO: o objetivo deste artigo é proporcionar uma reconstrução racional do programa de pesquisa do racionalismo neoclássico como um substituto para o programa do racionalismo clássico. O programa do racionalismo neoclássico se desenvolve pela elaboração de uma nova concepção de ciência que a demarque da metafísica, com a definição da ciência como representação em lugar de explicação. Esse programa é constituído de três subprogramas: o convencionalismo/pragmatismo de Poincaré, o realismo convergentista de Duhem e o empirismo lógico.

PALAVRAS-CHAVE: Convencionalismo. Realismo estrutural convergente. Racionalismo neoclássico.

O objetivo deste artigo é uma reconstrução racional do programa de pesquisa (LAKATOS, 1984) do racionalismo neoclássico como um substituto para o programa do racionalismo clássico (CHIAPPIN, 1996; CHIAPPIN; LEISTER, 2009). O programa racionalista neoclássico tem como principal objetivo a elaboração de uma nova concepção de ciência, particularmente de física, que se contraponha à concepção metafísica do programa do racionalismo clássico. Isso exige alterações axiológicas, epistemológicas, ontológicas, metodológicas e, principalmente, uma mudança na natureza do conhecimento, que passa de conhecimento com certeza para conhecimento hipotético. O programa

\footnotetext{
${ }^{1}$ Prof. Dr. (Associado) Departamento de Economia/FEA - USP. Ph.D pela University of Pittsburgh em Filosofia. Doutor em Física pela USP. Doutor em Economia pela USP. Endereço eletrônico: chiappin@usp.br.

2 Departamento de Economia-FGVSP. Graduada, Mestre e Doutora em Filosofia-USP. Graduada em Psicologia - PUC. Graduanda em Direito - USP. Pós-Doutoranda - Departamento de Economia - USP. 
neoclássico pode ser decomposto em três subprogramas segundo suas estratégias de contraposição à concepção metafísica: o subprograma do convencionalismo/ pragmatismo de Poincaré; o subprograma da teoria normativa da dinâmica das teorias científicas com convergência para a verdade de Duhem; e o subprograma do positivismo lógico.

O primeiro subprograma, elaborado por Poincaré, consiste na construção de uma concepção de ciência que se articula em torno de um modelo de escolha racional com incerteza subjetiva. Esse modelo rejeita o princípio da unidade lógica da ciência (PUL) e defende o princípio da subdeterminação da teoria pelos dados empíricos (PSTD) (POINCARÉ, 1891). Esse princípio, por sua vez, rejeita a ideia de que o método experimental proporciona decisões conclusivas e, portanto, rejeita o estatuto cognitivo da ciência, reduzindo seu valor a um valor puramente instrumental. Com isso, ele projeta uma concepção da ciência com característica convencionalista/pragmatista, em que a escolha de teorias se articula em torno de critérios com tons subjetivos (POINCARÉ, 1891; 1901; 1902)

O segundo subprograma, elaborado por Duhem, consiste na construção de uma concepção de ciência que rejeita, por um lado, a concepção metafísica e, por outro, a concepção pragmatista de Poincaré, sustentada na crença num modelo metodológico de escolha racional com certeza quanto às decisões pela falsidade, contrário à possibilidade de um modelo com certeza pela verdade, como queriam os metafísicos clássicos. Duhem assume compromissos extralógicos para elaborar uma teoria normativa da ciência, uma teoria dinâmica do crescimento científico, que tem no seu núcleo de racionalidade a adesão ao princípio da unidade lógica da ciência e ao pressuposto da existência de uma teoria transcendental da física com características de um realismo estrutural. Assim, a concepção de Duhem figura como termo médio entre a concepção metafísica e a convencionalista/ pragmatista (CHIAPPIN, 1989, Capítulo 3), e, pretende encontrar critérios objetivos, ainda que metodológicos, na escolha de teorias.

O terceiro subprograma, o positivismo lógico, faz uso do modelo de escolha racional com incerteza objetiva (confirmação), com características empiristas.

Este artigo trata apenas dos dois primeiros subprogramas: o subprograma do racionalismo neoclássico elaborado por Poincaré e o subprograma do racionalismo neoclássico de Duhem. Se, por um lado, este último se propõe, com Poincaré, recolocar em novas bases epistemológicas e metodológicas a concepção da teoria física, demarcando-a da concepção metafísica do racionalismo clássico (CHIAPPIN, 1996; CHIAPPIN; LEISTER, 2009), por outro lado, procura também evitar o radicalismo da proposta de Poincaré, que rejeita, com seu pragmatismo e ceticismo, um estatuto cognitivo para a ciência e a reduz a um 
valor puramente instrumental, assentado nos novos instrumentos emergentes da ciência, que enfatizam indeterminações e incertezas inerentes às teorias físicas, que ele mesmo desenvolveu e estão relacionados, principalmente, com a natureza da mecânica analítica, com seus infinitos modelos de massas e velocidades para uma mesma relação quantitativa (POINCARÉ, 1901), e com os sistemas dinâmicos da teoria do caos (RUELLE, 1993).

\section{I - O PROGRAMA DO RACIONALISMO CLÁSSICO}

Inicialmente, pretende-se fazer uma panorâmica dos principais traços do programa do racionalismo clássico, uma vez que o programa racionalista neoclássico pretende substituí-lo. Se, por um lado, o racionalismo neoclássico critica e rejeita muito dos principais pressupostos do racionalismo clássico, por outro lado, ele mantém alguns de seus postulados, entre os quais o de ser caracterizado por um conceito de racionalidade criterial no sentido de uma racionalidade operacionalizada por meio de regras e critérios.

O programa do racionalismo clássico desenvolveu-se em torno da construção do conceito de racionalidade como um método de escolha racional com certeza (CHIAPPIN, 1996, CHIAPPIN; LEISTER, 2009). Esse método pretendia possibilitar decisões acerca do valor de verdade das proposições de modo conclusivo, a partir de uma base do conhecimento formada de proposições verdadeiras estabelecidas com certeza. $\mathrm{O}$ modelo de organização do conhecimento do racionalismo clássico é a geometria. O método de escolha racional espelhou-se nos métodos de prova da geometria e da álgebra e, em particular, no método de prova por redução ao absurdo.

A concepção de racionalidade como um processo de decisão, presente no programa racionalista, foi formulada pela primeira vez por Descartes, para quem "[...] son entendement montre à sa volonté le choix qu'il faut faire" (DESCARTES, 1963, tomo I, p. 79). Tal racionalidade é denominada criterial, devido à exigência do uso de um método como conjunto de regras e critérios para sua aplicação (DESCARTES, 1963, tomo I, p. 90-99). Em síntese, o programa racionalista define que a racionalidade é um processo de tomada de decisões conduzido por meio de um método como um conjunto de regras e critérios. O programa racionalista criterial pode ser decomposto em três subprogramas: racionalista clássico (CHIAPPIN, 1996; CHIAPPIN; LEISTER, 2009), neoclássico e crítico (CHIAPPIN, 2008). O programa racionalista envolve também três modelos de escolha racional como ideia nuclear: o modelo de escolha com certeza, o modelo de escolha com incerteza objetiva e o modelo de escolha com incerteza subjetiva (CHIAPPIN, 1996). 
Esses modelos têm como pressuposto a decisão ou escolha quanto a uma unidade epistêmica. A unidade epistêmica é a forma de organização do conhecimento, como a proposição, a teoria, o modelo, o programa de pesquisa, o paradigma etc. Outros pressupostos são, por exemplo, aqueles de um método para construção das unidades epistêmicas e de uma forma de representação do conhecimento atribuída à unidade epistêmica. Nesse caso, a mesma informação material pode, por exemplo, em física, ser representada por meio da álgebra, por matriz, por vetores, por grupos etc. Essas representações têm tido um papel heurístico fundamental, no desenvolvimento da ciência, ainda a ser devidamente avaliado. O programa racionalista comporta métodos heurísticos e um método de escolha de unidades epistêmicas com algum critério de performance.

O modelo de escolha racional que define o conceito de racionalidade é um procedimento governado por um método capaz de proporcionar decisões com respeito ao valor de verdade das unidades epistêmicas bem estabelecidas. Esse modelo consiste, de modo abstrato e ideal, da maximização ou minimização de uma função que se encontra submetida a restrições. Os exemplos mais bem acabados desse modelo são: o modelo da mínima ação da física (LANCZOS, 1970), o modelo do utilitarismo de Bentham (CHIAPPIN; LEISTER, 2007), o modelo de escolha racional da microeconomia (VARIAN, 2006) e o modelo da termodinâmica de Gibbs, com suas funções de energia e entropia e os princípios de minimização e maximização (CALLEN, 1985). Contudo, a origem desses modelos está na geometria: no caso de Descartes, trata-se do problema da figura com a maior área para um dado perímetro (DESCARTES, 1963, tomo I, regra I, p. 72), da sua teoria do arco-íris e do problema do prisma com o ângulo mínimo (DESCARTES, 1963, tomo I, p. 749-761)33.

O subprograma do racionalismo clássico tem como objetivo epistemológico central a investigação das condições de possibilidade do conhecimento (CHIAPPIN, 1989; 1996; 2009) e como objetivo científico a construção da concepção metafísica da mecânica. Sua principal tese ontológica é que a natureza é extensão (matéria) e movimento. Suas principais teses epistemológicas são que a natureza do conhecimento é a certeza e que o sujeito tem faculdades que lhe permitem ter acesso direto à verdade das proposições. É uma epistemologia com sujeito. O racionalismo clássico pressupõe também que o modelo de organização do conhecimento é a geometria, na forma de um conjunto de proposições organizadas num sistema axiomático, constituído por uma base com um número mínimo de conceitos primitivos e proposições verdadeiras conhecidas como certas e que satisfaz o princípio da unidade lógica. O racionalismo clássico

${ }^{3} \mathrm{O}$ modelo geométrico será aplicado na política por Hobbes, que busca, na figura do Leviatã, a maximização do poder político. 
professa também a crença na existência de uma base última do conhecimento formada de proposições verdadeiras conhecidas como certas e de um método, definido como um conjunto de regras, que é o modelo de escolha racional com decisões conclusivas a respeito da verdade e da falsidade das proposições.

A aplicação do princípio da unidade lógica, seguindo o modelo geométrico de organização do conhecimento, consiste em assumir que a teoria era organizada num todo fortemente conectado e consistente, e também que essa unidade da teoria física era realizada pela mecânica. Essa aplicação do princípio da unidade lógica por meio da mecânica consiste na construção ontológica de um mundo formado de matéria, corpúsculos em movimento segundo os princípios da conservação da quantidade do movimento, da lei da inércia e da lei dos choques. Isso significou a imposição metafísica de que toda explicação legítima dos fenômenos naturais tivesse que ser uma explicação mecanicista. Essas explicações eram elaboradas por meio da construção de modelos mecânicos formados de massas em movimento. O método de construção de modelos mecânicos consistia em fazer uso de massas invisíveis em movimento como explicações dos fenômenos naturais. Esse método se desenvolveu de modo semelhante àquele da geometria, tanto em seu aspecto analítico quanto sintético.

A unidade epistêmica do programa do racionalismo clássico não é a teoria, mas os conceitos e as proposições. As proposições são consideradas verdadeiras ou falsas. As teorias da verdade são aquelas da correspondência e da consistência. Ainda que faça uso sistemático do princípio da unidade lógica, decorrente do modelo geométrico, a abordagem analítica privilegia os princípios da separabilidade e da testabilidade isolada das proposições (CHIAPPIN, 1989). Com esses recursos, o objetivo do método de escolha é decidir de modo conclusivo o valor de verdade de uma dada proposição (como, por exemplo, a lei da refração) por meio da construção, com ajuda de modelos mecânicos, de uma prova, a partir dos princípios da mecânica (DESCARTES, 1963, tomo I, p. 658-677). O modelo de escolha deve permitir decidir se a lei pertence ou não ao sistema de conhecimento caracterizado pela base do conhecimento. A integração de uma lei empírica na teoria física é que a transformaria num conhecimento certo, desde que não estivesse envolvido o uso de hipóteses como vínculos intermediários. Nesse caso, não haveria conhecimento certo, mas certeza moral, de caráter prático. Contudo, tem-se nessa situação apenas um conhecimento provisório.

No caso da teoria física, a aplicação desse método de escolha racional com decisão conclusiva pela verdade e pela falsidade leva à interpretação de que o método experimental realiza uma experiência crucial. É o caso do método de prova por redução ao absurdo, que possibilita decidir de maneira conclusiva tanto pela verdade quanto pela falsidade das proposições científicas. O modelo desse 
método de escolha é o Experimentum Crucis. A aplicação desse método em física se expressou na ideia de que se estava diante de um Experimentum Crucis como utilizado por Newton, em sua teoria das cores (NEWTON, 1672; SILVA, 1996; 2003). Newton tinha a intenção de usar a experiência dos prismas para mostrar que as cores não eram criadas, mas separadas da cor branca pelos diferentes graus de refrangibilidade (SILVA, 2003). A origem dessa concepção de experimento crucial aparece pela primeira vez, em Bacon, com o nome de instâncias cruciais (BACON, seção XXXVI, 1984).

A metafísica de Descartes, construída nas Meditações (DESCARTES, 1967, tomo II) como base do conhecimento é um exemplo bem acabado dessa imagem da construção típica da concepção metafísica da ciência, para a qual a natureza do conhecimento é a certeza. O método da dúvida desempenha nas Meditações o papel do método heurístico, como método analítico, e do método de redução ao absurdo, para a construção da base do conhecimento de sua concepção metafísica formado de proposições verdadeiras conhecidas como certas.

O método analítico (DESCARTES, 1967, tomo II, p. 581) é um método de construção da base formada dessas proposições verdadeiras conhecidas como certas. Essas proposições, nas Meditações, são, por exemplo, "Eu sou”, "Eu existo", "Eu sou uma coisa que pensa", "O espírito é mais fácil de conhecer que o corpo", "Deus existe”, "Deus é veraz” etc. (DESCARTES, 1967, tomo II, p. 414454). Na elaboração dessas verdades (proposições) opera o método de escolha, que é o método analítico, que possibilita aceitar e rejeitar novas proposições. Ele constrói a prova da existência de Deus e de que ele é veraz e, concomitantemente, como um experimento crucial, seguindo o modelo do método de redução ao absurdo, rejeita a proposição de que existe um Gênio Maligno que aparece como hipótese, na primeira meditação. O elemento central dessa concepção da ciência é a construção de um sujeito transcendental equipado epistemologicamente para conhecer diretamente as essências do mundo, estabelecidas como mecânicas, que são matéria (extensão) e movimento. Esse é o modo de construir a base do conhecimento formado de proposições verdadeiras conhecidas como certas.

O subprograma do racionalismo clássico é formado hipoteticamente por uma sequência de quatro teorias do conhecimento: a teoria cartesiana, a teoria lockeana, a teoria humeana e a teoria kantiana (CHIAPPIN, 1996; 2009). Essas teorias partilham do núcleo do programa com as principais teses ontológicas, epistemológicas e axiológicas, tais como: (i) a construção de uma concepção autônoma da ciência independente, por um lado, da religião e, por outro, do ceticismo; (ii) a ideia de que o conhecimento é certo e o método é necessário para alcançar a verdade (DESCARTES, 1963, tomo I, p. 80, 90), ou seja, a rejeição 
de toda possibilidade de se reconhecer o hipotético como conhecimento e a probabilidade como instrumento epistêmico.

Contudo, o subprograma de pesquisa racionalista clássico verificou ser degenerativo em seus aspectos epistemológico e científico. A restrição de que o conhecimento é certo teve que ser abandonada, em favor da ideia de que o conhecimento é hipotético e a imposição da mecânica como unidade da ciência também teve de ser abandonada, devido à emergência de novos domínios da física, como termodinâmica e eletromagnetismo. Com isso, o programa perde sua capacidade de resolver problemas no interior de um quadro teórico extremamente restritivo, que exige que suas proposições sejam verdadeiras e conhecidas como certas e que toda explicação seja mecânica. O programa racionalista clássico se viu cerceado em sua pretensão de consolidar seu propósito de transformar em ciência, pelo método, diversas áreas do conhecimento, tais como a metafísica, a moral, a física, a medicina. À medida que o progresso científico avançou, observou-se o oposto daquele propósito, ou seja, o encolhimento sistemático dos domínios do racionalismo clássico como conhecimento certo, até que fosse reduzido a um conjunto vazio em decorrência do veredicto de que não há conhecimento certo, nem método que o produza, mas apenas conhecimento hipotético, e de que as teorias sofrem ascensão e queda, em suas pretensões de proporcionar um conhecimento verdadeiro da natureza do mundo.

A degeneração do programa decorreu inicialmente em virtude das análises epistemológicas de Locke sobre o pressuposto cartesiano de que o conhecimento é conhecimento certo. Na teoria do conhecimento de Descartes, a metafísica, a física, a moral, a mecânica e a medicina deveriam ser estabelecidas como conhecimento certo (DESCARTES, 1971, tomo III), como expressa sua metáfora da árvore do conhecimento. A análise de Descartes elimina do campo da ciência todas aquelas disciplinas que não são passíveis de construção como conhecimento certo, por meio do método, exceto a moral. A concepção de Locke recorre à tese epistemológica do empirismo segundo a qual todo conhecimento provém dos sentidos e à distinção entre essência nominal e essência real. (LOCKE, [1973]). Ele chega à conclusão de que as leis da física não preenchem as exigências do conhecimento certo, assim como a metafísica, a medicina e a mecânica. Suas leis não podem ser consideradas proposições universais e necessárias, pois o conhecimento das essências reais é inacessível aos métodos racionais empíricos (CHIAPPIN; LEISTER, 2009).

De acordo com Locke, apenas a moral é conhecimento certo, uma vez que, como a geometria, nela há uma coincidência entre essência nominal e real por construção de seus objetos (LOCKE, 1973). Por definição, a construção de um objeto geométrico captura tanto sua essência nominal quanto sua essência real, 
como acontece com a definição de triângulo. A moral segue esse procedimento de construção de conceitos e proposições.

Hume conduz essa análise aos seus limites, fazendo uma distinção ainda mais clara e operacional entre proposições sintéticas e analíticas (HUME, 1973). As proposições analíticas têm seu valor de verdade obtido a partir da análise da estrutura formal da proposição e não se referem ao mundo real. Elas não são proposições de conhecimento, mas proposições auxiliares para a explicitação e esclarecimento das definições e termos envolvidos no discurso. Já o valor de verdade das proposições sintéticas depende da experiência empírica, todavia, não há como garantir a verdade das proposições universais e, portanto, das leis científicas, com base na experiência, que pode gerar apenas proposições particulares. Segue-se, pela mesma razão, que a moral, por conter proposições sintéticas, não pode ser conhecimento certo. Em lugar do conhecimento que é objeto de certeza, Hume ${ }^{4}$ afirma que temos crenças, proposições de natureza hipotética, acerca dos fenômenos, que é o que pode ser gerado pelo método experimental.

A teoria kantiana é uma tentativa de amparar a proposta de Descartes, de conhecimento como conhecimento certo, porém, desenvolvida a partir da crítica de Hume, com a construção dos juízos sintéticos a priori. Contudo, a proposta kantiana não se sustenta, ainda que desta vez não mais por causa de argumentações epistemológicas, mas do desenvolvimento científico. A concepção kantiana do juízo sintético a priori não pôde sobreviver ao desenvolvimento posterior da ciência. Esse desenvolvimento mostrou com sistematicidade a refutação e a rejeição de teorias que tinham sido consideradas anteriormente verdadeiras e foram substituídas por outras. Exemplos dessas teorias refutadas pela experiência são: a substituição da teoria do calórico pela teoria mecânica do calor e a emergência da autonomia da teoria eletromagnética e da termodinâmica relativamente à mecânica, estabelecendo definitivamente a ideia de que as teorias ou leis científicas são conjuntos de hipóteses e não sistemas de proposições verdadeiras, e de que, aparentemente, estão sujeitas a movimentos alternados de ascensão e queda.

O desenvolvimento da análise lógica do método científico revelou, além do caráter hipotético das proposições científicas, que não era possível a tese clássica da separabilidade e testabilidade isolada das hipóteses. O próprio Kant já afirmara que não há dados brutos, mas dados interpretados, e que o método de teste não é conclusivo quanto ao valor de verdade das proposições. O desenvolvimento científico na matemática trouxe novas geometrias, como a geometria riemanniana, que são corpos axiomáticos consistentes com postulados completamente diferentes e mesmos opostos àqueles da geometria euclidiana.

${ }^{4}$ HUME, 1980, p. 96. 
Não só o espaço físico da concepção kantiana (KANT, 1974) é aquele da geometria euclidiana, no entanto, ela é tomada como paradigma da cientificidade, uma vez que fornece exemplares das proposições consideradas juízos sintéticos $a$ priori, que são opostos àqueles da geometria de Riemann.

O próprio desenvolvimento da mecânica fez evoluir seus instrumentos, transformando-os em linguagens. As representações de Lagrange e Hamilton (DUGAS, 1988; LANCZOS, 1970) são transformadas, com seus espaços artificiais, em recursos de solução de problemas, revelando-se mais adequadas para organizar domínios da ciência e prescindindo cada vez mais de considerações sobre a natureza da matéria. O principal desses instrumentos é o método analítico de construção da mecânica com o princípio da ação mínima. A natureza do método analítico permitiu reduzir os princípios da mecânica de Newton a um único princípio, praticamente matemático, o da ação mínima, e gerar diferentes representações da mecânica, dependendo do tipo de variáveis com que se pretende lidar, definindo ou um espaço de configuração ou um espaço de fase.

O mesmo desenvolvimento mostrou a emergência de domínios que se pretendem autônomos, como a termodinâmica e o eletromagnetismo, porque resistem a serem reduzidos a explicações mecânicas. Evidenciou ainda sucessivas refutações e rejeições de teorias físicas e suas substituições por outras, tais como o caso da teoria do calórico substituída pela teoria mecânica do calor. Os estudos de Maxwell sobre o eletromagnetismo revelaram uma nova legitimidade da ciência com sua aplicação da abordagem mecânica analítica ao eletromagnetismo em substituição à abordagem sintética, prescindindo, portanto, da construção de modelos concretos constituídos por massas em movimento. Essa exigência dava origem a modelos bizarros, no cumprimento da aplicação do princípio da unidade lógica por meio das explicações mecânicas, segundo o qual todo fenômeno deveria ser mecânico.

A emergência da abordagem analítica da mecânica com a construção da mecânica analítica e sua obtenção a partir de um único princípio de natureza quase puramente matemática, como o princípio da mínima ação, assim como de áreas autônomas, como a da termodinâmica e do eletromagnetismo, criaram uma atmosfera na qual se tornou imperativa uma reflexão sobre os fundamentos dessa nova física. A mecânica analítica substituiu o método sintético de construir a explicação mecânica com modelos concretos mecânicos, por conseguinte, formados de matéria em movimento, e dotou a mecânica de instrumentos heurísticos poderosos, entre os quais, como mencionado, as representações diferentes do mesmo fenômeno, que são a mecânica lagrangeana e a hamiltoniana, e os sistemas dinâmicos com hipersensibilidade de suas condições iniciais. A termodinâmica e o eletromagnetismo emergiram como disciplinas autônomas, 
sustentadas sobre seus próprios postulados e conceitos, não se submetendo às exigências de exibirem explicações por meio de modelos mecânicos.

Tais representações da mecânica foram interpretadas por Duhem como uma linguagem e não como uma mecânica com a respectiva ontologia, que, portanto, poderiam ser utilizadas para organizar outras áreas da física, as quais estariam totalmente desvinculadas de uma ontologia mecânica. Os exemplos são dados pelo próprio Maxwell, com o eletromagnetismo que ele constrói em termos da representação lagrangeana, mas dissocia da construção de modelos mecânicos como havia feito anteriormente em suas primeiras tentativas de construir um eletromagnetismo, e por Gibbs, com a termodinâmica que é construída em termos axiomáticos, com base na função energia e do princípio de minimização. Samuelson vai usar o mesmo instrumental da termodinâmica de Gibbs, para organizar formalmente a microeconomia. Graças à representação lagrangeana, a microeconomia é uma termodinâmica.

A epistemologia, a ontologia, a axiologia e a metodologia do racionalismo clássico (CHIAPPIN; LEISTER, 2009) precisavam ser substituídas por uma nova teoria da ciência que trouxesse outra concepção de ciência mais ajustada a esses novos contornos do conhecimento científico e sua legitimidade. Nesse contexto, Maxwell, Boltzmann, Duhem e Poincaré (e Pareto, na economia) vão construir o programa de pesquisa do racionalismo neoclássico para substituir o racionalismo clássico. Neste artigo, focalizamos a construção do racionalismo neoclássico conforme os subprogramas de Duhem e Poincaré.

O objetivo do programa do racionalismo neoclássico é construir uma concepção de ciência que a demarque da concepção metafísica da ciência e rejeite definitivamente a ideia da possibilidade do acesso direto ao conhecimento certo. Tanto Poincaré como Duhem, mas principalmente Duhem, buscam reavaliar criticamente a proposta do racionalismo clássico e desenvolver uma nova teoria da ciência, com uma nova ontologia, epistemologia, axiologia e metodologia, para descrever a natureza da teoria física e do seu progresso, tendo como ponto de partida o caráter hipotético-dedutivo da pesquisa científica. Em oposição à concepção clássica, Duhem observa:

\footnotetext{
As teorias físicas não progridem como as teorias matemáticas, pela contínua introdução de novas proposições, definitivamente demonstradas, que se unem a proposições já reconhecidas como certas. (DUHEM, 1895a, p. 27).
}

Contudo, como veremos, se Duhem e Poincaré partilham do mesmo objetivo de construir uma definição de teoria física, de modo a demarcá-la da metafísica, Duhem não partilha da concepção convencionalista/pragmatista de 
Poincaré, esforçando-se em desenvolver estratégias ontológicas, epistemológicas, axiológicas e metodológicas para sua concepção de física que o demarquem da concepção do convencionalismo/pragmatismo de Poincaré.

\section{II - O PROGRAMA DO RACIONALISMO NEOCLÁSSICO: O SUBPROGRAMA convencionalista/pragmatista de Poincaré}

Poincaré desenvolve uma concepção de teoria física com o objetivo de demarcá-la da concepção metafísica da ciência segundo o racionalismo clássico. Essa concepção é partilhada por Duhem em sua oposição à concepção metafísica. Pressupomos aqui que ambos desenvolvem um programa de pesquisa neoclássico sobre a natureza, a estrutura e o objeto da teoria física que tem em comum sua oposição à concepção metafísica da ciência. No entanto, devido às profundas peculiaridades e diferenças entre eles, podemos considerar que eles constroem dois subprogramas do programa de pesquisa neoclássico: o subprograma neoclássico convencionalista/pragmatista de Poincaré e o subprograma do realismo estrutural de Duhem. Para ambos, o objetivo é demarcar a teoria física da metafísica, e para esse fim eles constroem a física teórica com o objetivo de sistematização e organização das leis empíricas.

No intuito de demarcar a teoria física da concepção metafísica, Poincaré apresenta a seguinte definição de teoria física:

O objetivo da teoria matemática não é nos revelar a natureza real das coisas; esta seria uma exigência irrealizável. Seu único objetivo consiste em coordenar as leis físicas com as quais a experiência nos familiariza [...]. (POINCARÉ, 1952, p. 211)

Essa definição, como a de Duhem, se opõe à definição dos clássicos, de acordo com os quais a teoria física tem por objetivo proporcionar explicações dos fenômenos naturais, entendendo por explicações a indicação das causas reais das coisas.

Para Poincaré, a ideia relevante está relacionada à coordenação das leis físicas. Essa coordenação pode ser efetivada por algum princípio matemático ou físico, cujo único propósito é introduzir ordem e classificação nas leis da física. Ele tem o objetivo de produzir uma organização entre elas. Não há pretensões ontológicas de capturar as causas reais da produção dessas leis. Com essa definição, Poincaré procura operacionalizar a demarcação da concepção metafísica por meio de um procedimento de controle como aquele de um método de construção da teoria física que evite o apelo às causas reais e se sirva apenas de princípios matemáticos organizadores, ordenadores, coordenadores ou classificadores das leis empíricas. 
Nessa proposta de definição de teoria física associada a um método de construção, Poincaré se limita a dois recursos metodológicos: a análise puramente lógica do método científico e o método experimental. Segundo Poincaré, não há necessidade de apelar para qualquer outro instrumento de análise, a fim de entender e estudar a natureza da teoria física.

A definição da teoria física é o ponto de partida de Poincaré para desenvolver uma imagem da física em oposição à metafísica. Tal proposta de definição e sua restrição aos dois recursos metodológicos se desenvolvem numa forma bastante radical de concepção da teoria física com contornos de um pronunciado ceticismo/relativismo. Poincaré leva sua análise lógica da teorização científica (em particular, a abordagem mecânica de Maxwell da teoria eletromagnética) e a análise do método experimental ao seu fim natural (VICAIRE, 1893, p. 476), que é o princípio da subdeterminação da teoria pelos dados. Esse princípio apela, em sua forma mais radical, ao uso legítimo de teorias incompatíveis para descrever o mesmo conjunto de leis. Ele rejeita, por conseguinte, um dos componentes da racionalidade clássica, o princípio da unidade lógica.

A partir de sua análise dos fundamentos da explicação mecânica, como dada por Maxwell em sua construção do eletromagnetismo com os recursos da mecânica analítica de Lagrange, Poincaré formula explicitamente, na seguinte passagem, o núcleo de seu programa metodológico para construir a teoria física:

\footnotetext{
Não devemos nos orgulhar de evitar toda contradição. Mas devemos tomar partido. Duas teorias contraditórias, com efeito, contanto que não as misturemos, e nem busquemos a essência das coisas, podem ambas ser instrumentos úteis de pesquisa. Talvez a leitura de Maxwell fosse menos sugestiva se ela não tivesse aberto tantos caminhos novos, divergentes. (DUHEM, 1974, p. 91; POINCARÉ, 1901, p. vi).
}

Denomino esse pronunciamento de Poincaré a "regra da subdeterminação". Poincaré argumenta a favor dessa abordagem, com sua análise da mecânica analítica de Lagrange, em termos heurísticos e históricos (POINCARÉ, 1901, introdução). Essa regra da subdeterminação estabelece que a física pode usar teorias distintas e incompatíveis (DUHEM, 1974, p. 330), sendo isso um corolário de uma tese mais forte, formulada por Poincaré, que nomeio de princípio da subdeterminação da teoria pelos dados (PSTD).

A decisão de Poincaré de aplicar o princípio da subdeterminação da teoria pelos dados (PSTD), em teoria física, rompe com um dos princípios do racionalismo clássico que é o princípio da unidade lógica (PUL), o qual aparece, como menciona Duhem na passagem abaixo, como seu princípio supremo: 
Entre um número de teses postuladas [autorizadas somente por razões estranhas à física], encontra-se a seguinte: a teoria física deve tentar representar todo grupo de leis naturais através de um único sistema, cujas partes são logicamente compatíveis entre si. (DUHEM, 1974, p. 293).

O princípio generalizado da subdeterminação (diferente da subdeterminação dos modelos mecânicos), tal como aplicado na física como um todo, é explicitamente formulado por Pareto com base no trabalho de Poincaré, tendo profundas consequências metodológicas para a imagem da física e mesmo da ciência, com respeito aos racionalistas clássicos. Com efeito, Pareto afirma:

Os mesmos fatos podem ser explicados por uma infinidade de teorias, igualmente verdadeiras, porque todas reproduzem os fatos a serem explicados. É neste sentido que Poincaré pôde dizer que do fato mesmo de que um fenômeno admite uma explicação mecânica, ele admite uma infinidade delas [...] (PARETO, 1909, p. 31-36, apud LATSIS, 1976, p. 9 - grifos nossos).

A adoção do princípio da subdeterminação da teoria pelos dados, no interior da concepção de Poincaré, tem três fontes principais: (1) os estudos de Poincaré acerca da geometria e da matemática (uma interpretação discutida por Grünbaum, 1968, p. 106-122, e Giedymin, 1982); (2) a análise crítica de Poincaré sobre os fundamentos da mecânica e do método mecanicista, baseada nos trabalhos de Maxwell sobre a teoria do eletromagnetismo; e (3) os sistemas dinâmicos com hipersensibilidade às condições iniciais, que ele mesmo desenvolveu.

Uma das consequências importantes desse exame crítico da abordagem da mecânica analítica é que, se tivermos um modelo mecânico, teremos um número infinito deles, que é exatamente o que diz Pareto (POINCARÉ, 1901, introdução).

Entretanto, qual a razão para essa afirmação? A razão está em que a mecânica lagrangeana mostrou a possibilidade de gerar infinitos modelos mecânicos para uma mesma base empírica, empregando a hipótese dos mecanismos invisíveis de massas ocultas em movimento. Tal hipótese gera indeterminação, uma vez que as massas (mi) e movimentos (velocidade; qi) usadas pela abordagem analítica são indeterminadas e arbitrárias. Esses conceitos funcionam como parâmetros de equações que devem ser ajustadas aos fenômenos explicados. As indeterminações das hipóteses de mecanismos de massas invisíveis em movimento proporcionam ao programa mecanicista os recursos para aplicar uma estratégia de subdeterminação da teoria pelos dados. É o que faz Poincaré, em sua análise dos assim chamados experimentos cruciais: os experimentos de Wiener (POINCARÉ 1891, p. 325329) e de Gouy (POINCARÉ, 1894, p. 226). 
As indeterminações introduzidas por essa hipótese são a origem do princípio da subdeterminação. Elas permitem a Poincaré afirmar que, se há um modelo mecânico, há uma infinidade deles (POINCARÉ ,1901, introdução). Esse enunciado o leva a declarar seu compromisso com a regra da subdeterminação (POINCARÉ 1901, introdução). O uso metodológico de indeterminações complica a aplicação do princípio da testabilidade empírica do racionalismo clássico, que afirma a separabilidade e a testabilidade das hipóteses. Não se pode aplicar efetivamente esse princípio empirista, quando a teoria física contém naturalmente os meios para evitá-lo, que são os estratagemas mencionados acima.

Poincaré faz extenso uso desses estratagemas de subdeterminação. Por exemplo, ele os emprega em sua análise do experimento de Wiener, formulado para decidir entre as teorias da luz de Neumann e de Fresnel, bem como em seu exame do experimento de Gouy, para decidir entre a teoria eletromagnética da luz e a teoria elástica da matéria.

Em meados do século XIX, aqueles que buscavam um método de construção de teorias físicas similar ao do método mecanicista, como Poincaré, substituíram a concepção metafísica da ciência pela pragmatista/convencionalista. Assim, o princípio da subdeterminação da teoria pelos dados tornou-se o principal elemento metodológico de demarcação da concepção metafísica. Nenhum modelo mecânico poderia ter pretensões de corresponder à natureza real do mundo, já que se poderia multiplicar a construção de outros modelos que se ajustam à mesma base empírica que deveriam representar.

Em sua análise histórico-crítica do mecanicismo, Duhem considera a indeterminação inerente à aplicação da abordagem analítica da mecânica como a principal razão para a falta de falseabilidade das teorias mecanicistas (DUHEM 1974, p. 281; 1980, p. 97-98) e para a ausência de um método regular para construir essa forma de explicação mecânica, o que torna sua formulação puramente conjectural (DUHEM, 1980, p. 79). A indeterminação das hipóteses de massas ocultas em movimento proporciona a Poincaré estratégias para evitar refutações cruciais. Ele faz do princípio da subdeterminação da teoria pelos dados (PSTD) um elemento efetivo de sua metodologia. Duhem declara (após citar Heaviside, Cohn e Hertz, que adotam esse mesmo ponto de vista) que o método de Poincaré, de construção de teorias físicas através da regra da subdeterminação, portanto com o uso de combinações de massas invisíveis em movimento, é definido em oposição à concepção racionalista clássica (unidade lógica, sistemas axiomáticos bem construídos etc.). Ele afirma:

Mais formalmente que Hertz, Poincaré proclamou o direito da física matemática de abalar o domínio de uma lógica demasiadamente rigorosa e de romper a conexão que unia suas diversas teorias umas às outras. (DUHEM, 1974, p. 91) 
Essa decisão de Poincaré é interpretada de modo similar por alguns de seus contemporâneos, tais como E. Vicaire. Segundo este:

\begin{abstract}
Não apenas na obra citada com freqüência [Poincaré 1901], ele [Poincaré] admite que as diversas teorias propostas para explicar os fenômenos óticos pelas vibrações de um meio elástico são igualmente plausíveis, mas ele parece abandonar como utópico e antiquado o princípio dos antigos teóricos da física segundo o qual nenhum surgimento de contradição é tolerado, e "é julgado necessário que as diversas partes sejam logicamente vinculadas umas às outras e que o número de hipóteses distintas seja reduzido ao mínimo". (VICAIRE, 1893, p. 476; grifos nossos).
\end{abstract}

Contudo, a radicalização de Poincaré não acaba com a adoção do princípio da subdeterminação com respeito à estrutura da teoria física do racionalismo clássico. Ele rompe também, devido à sua adoção do princípio da subdeterminação em substituição ao princípio da unidade lógica (PUL), com a ideia do método experimental como um método de prova para encontrar o valor de verdade das proposições científicas. Segundo Poincaré, não há experimentos cruciais que possam decidir entre teorias físicas rivais. $O$ método experimental não pode decidir de modo conclusivo nem pela verdade, nem pela falsidade. Dessa maneira, Poincaré questiona qualquer eficácia do modelo de escolha racional de teorias físicas. Temos aqui um ceticismo acerca do método experimental como modelo de escolha racional conclusiva entre teorias físicas rivais ou proposições rivais. A rejeição de um modelo de escolha racional com certeza tanto pela verdade quanto pela falsidade, como queriam os clássicos, resulta da aplicação sistemática, por parte de Poincaré, dessa estratégia metodológica de subdeterminação da teoria pelos dados (POINCARÉ, 1891, p. 326; QUINN, 1969, p. 398).

Como consequência, a escolha das teorias depende de outras características, além do método experimental, como critérios de consistência, de ordem, de beleza etc. Desse modo, Poincaré rejeita a possibilidade dos experimentos cruciais para escolher entre teorias e hipóteses alternativas, e torna não testáveis empiricamente tanto as teorias físicas e algumas de suas hipóteses, como as leis físicas fundamentais. Isto é, elas se tornam convenções. E sua escolha está mais próxima do modelo de escolha com incerteza subjetiva, ou seja, depende de certos valores do pesquisador. Esses dois aspectos contrários à visão clássica e ao princípio da unidade lógica e ao método experimental como método de prova, estão intimamente vinculados e formam um núcleo duro da racionalidade neoclássica.

Os geômetras, franceses em sua maior parte, que fundaram a física matemática, viam nas teorias que constituíam esta ciência a explicação racional, a razão de ser metafísica das leis descobertas pelos experimentadores; desde então, estas teorias, eles as queriam logicamente encadeadas. Esta maneira de compreender 
o papel das teorias da física matemática tende, hoje, a ser abandonada. (DUHEM, 1893b, p. 364).

Entretanto, o pragmatismo/convencionalismo mantém outras teses empiristas dos racionalistas clássicos, tais como o princípio de que todo conhecimento é empírico e, principalmente, o princípio da separabilidade e testabilidade de hipóteses isoladas.

As outras teses da concepção pragmatista/empirista são: (1) as teorias são apenas um meio de classificação, sendo usadas como instrumentos para pesquisa (a física teórica possui somente um valor técnico e utilitário) (DUHEM, 1974, p. 330); (2) a física pode, por conseguinte, empregar simultaneamente teorias distintas e incompatíveis; (3) a lógica e o método empírico são os únicos meios legítimos para examinar criticamente as teorias físicas; e (4) não há outras verdades em física além dos fatos experimentais.

Como veremos, Duhem vai questionar a aceitação de todas essas teses, por parte do convencionalismo/pragmatismo.

A consequência lógica e metodológica da adesão ao princípio da subdeterminação da teoria pelos dados, com a rejeição da unidade lógica, e da adesão à ideia de que o método experimental não é um método de prova capaz de construir um Experimentum Crucis, como também queriam os clássicos, é que as teorias físicas só podem ter um valor prático e instrumental, e não um valor objetivo, de conhecimento. Como pensar num valor objetivo, quando se admite metodologicamente a utilização de hipóteses contraditórias no interior da teoria física, tal como autorizada pelo princípio da subdeterminação da teoria pelos dados? Eis o valor da teoria física para os convencionalistas/pragmatistas: valor prático e instrumental (DUHEM, 1974, p. 330).

Segundo Duhem o pragmatismo de Poincaré, proveniente de Maxwell, é necessariamente um desdobramento consistente de sua adesão à análise lógica da ciência e ao método experimental como os únicos instrumentos legítimos de abordagem da ciência, recusando qualquer consideração extralógica. Essa concepção pragmatista de que as teorias físicas são receitas pode ser traduzida nas seguintes palavras:

O pragmatismo contemporâneo afirmou que as teorias físicas não possuem um valor como conhecimento, que a função delas é inteiramente utilitária, e que elas são, em última análise, apenas "receitas convenientes" que nos permitem agir "com sucesso" sobre o mundo externo. (DUHEM, 1974, p. 314). 
Duhem considera a análise de Poincaré acerca da concepção clássica demasiadamente radical e, ao mesmo tempo, muito pouco crítica, uma vez que Poincaré emprega, no interior da mesma metodologia, princípios empiristas - tais como o princípio da separabilidade e testabilidade isolada de hipóteses, a tese da separação entre teoria e observação, o uso do método indutivista - e princípios de natureza antiempirista, alguns já analisados, tais como a tese da não testabilidade empírica de certas leis (convenções), a ideia de que o método experimental não é um método de prova e o princípio da subdeterminação da teoria pelos dados.

Outra crítica de Duhem a Poincaré, em sua análise da teoria da física, é que este emprega elementos metodológicos mais próprios à ciência natural para avaliar a teoria física como física matemática, por exemplo, o princípio da testabilidade isolada de hipóteses e o método indutivo. Para Duhem, esses elementos metodológicos são inadequados para a teoria física como física matemática já que a natureza da teoria física como física matemática envolve uma interpretação teórica que torna inviável a adoção do método indutivo como o princípio da separabilidade e testabilidade isolada de hipóteses.

Esse elemento novo importante e não levado em conta por Poincaré é que os fatos empíricos são teoricamente impregnados (DUHEM, 1974, p. 322). Seguese que não há separação entre teoria e base empírica, pois todos são expressos por proposições. A distinção está no conteúdo empírico. Dessa forma, segundo Duhem, não há fatos brutos. Isso exige que se pense a física matemática como um sistema interconectado de conceitos, leis e fatos impregnados de teorias. Poincaré não reconhece, no entanto, esse aspecto da física matemática (DUHEM, 1974, p. 149). Há, sim, na perspectiva de Poincaré, distinções entre as proposições no sentido que algumas são convenções, portanto, irrefutáveis por definição, e as demais, proposições empíricas. Ele apenas combina características próprias a ciências distintas, tais como as ciências naturais e a matemática.

Esse elemento novo tem outras consequências, fazendo da teoria física, como física matemática, no entender de Duhem, algo mais do que a mera combinação de ciência experimental e matemática. Assim, por exemplo, ela não pode ser considerada como uma soma de proposições, mas como um sistema interconectado de proposições que não podem ser separadas e isoladas, para serem testadas uma por uma. Ela tem sua natureza associada ao princípio da unidade lógica, ou seja, da necessidade de consistência e coerência interna do sistema de conceitos e proposições. A consequência dessa interpretação é de que a testabilidade da teoria é quanto ao sistema como um todo e, portanto, não cabe mais a concepção clássica do método de testabilidade de proposições separadas e avaliadas isoladamente. 
Ao contrário dessa posição, Poincaré opta, como mencionado anteriormente, por aplicar a regra da subdeterminação em teoria física, segundo a qual, se há um dado modelo formando a representação de amplo conjunto de fatos, então há infinitos modelos que são capazes de proporcionar outras representações para o mesmo conjunto de dados. Esse argumento da subdeterminação da teoria pelos dados empíricos serve para rejeitar o método experimental como método de prova, conduzindo à formulação das teorias físicas como formadas de convenções e reduzindo a teoria física a apenas um valor instrumental sem valor objetivo. A consequência desse compromisso com o princípio da subdeterminação tem como resultado transformar Poincaré naquele que originou a concepção convencionalista/ pragmatista na França. Duhem afirma:

E não são esses prefácios retumbantes acerca dos trabalhos de Maxwell, feitos pelo distinto professor Poincaré da Sorbonne, aqueles que deram origem na França à crítica pragmatista da física, contra a qual M. Rey hoje protesta? (DUHEM, 1974, p. 319).

Como mencionado anteriormente, essa crítica pragmatista é vista por Duhem como uma nova fonte de ceticismo (neoceticismo) (DUHEM, 1900b, p. 251). Como Duhem detecta que há uma forte tendência geral da concepção moderna de teoria física, na direção de uma visão convencionalista/empirista, e entende que esta se baseia em análises epistemológicas e metodológicas inadequadas da natureza da teoria física como física matemática, se ele se propõe, por um lado, combater ao lado de Poincaré a concepção metafísica das explicações causais, por outro, e, principalmente, ele almeja, fundamentalmente, procurar evitar que essa demarcação da metafísica se transforme numa abordagem convencionalista/ pragmatista da ciência, como quer Poincaré.

A concepção pragmatista/empirista na França, com Poincaré, tem origem na visão inglesa do mecanicismo, com Maxwell, que rejeita a construção de teorias físicas em conformidade com os valores racionalistas, de tradição francesa, tal como o princípio da unidade lógica, exigindo apenas a adequação empírica das teorias (POINCARÉ, 1901). Essa proposta argumenta a favor de se ater a uma análise lógica da teorização científica, que, associada ao método empírico, deve proteger a ciência da metafísica e de outras interferências especulativas. Mas, por outro lado, não se preocupa com a organização racional da teoria, com seu sistema axiomático, em particular, com o princípio da unidade lógica, muito caro à concepção racionalista da ciência.

Para essa concepção pragmatista, a crítica puramente lógica da ciência e a abordagem empirista, com o método experimental, são suficientes para garantir a autonomia do domínio científico, libertando-o dos estreitos vínculos metafísicos. 
No entender de Duhem, o resultado dessa oposição radical à metafísica é uma concepção de ciência que possui fortes implicações céticas. Denomino, seguindo Abel Rey (REY, 1904, p. 722), tais implicações de "neoceticismo", para distinguilas do ceticismo resultante da combinação de metafísica com física. Este último gera o pessimismo histórico. A concepção racionalista da ciência de Duhem tem como importante preocupação evitar esses dois tipos de ceticismo.

De acordo com Duhem, contudo, existe um conflito ou uma tensão entre a metodologia instrumental de Poincaré e seu instinto natural, como um físico que reconhece a importância da aplicação do princípio da unidade lógica e atribui um valor objetivo à teoria física. Duhem salienta tal ambivalência no trabalho de Poincaré com as seguintes palavras:

O escrutínio lógico que ele desenvolveu com impiedoso rigor levou Henri Poincaré a um beco com a seguinte conclusão bastante pragmática: a física teórica é apenas uma coleção de prescrições. Contra esta proposição, ele empreendeu um tipo de revolução, tendo proclamando, com veemência, que a teoria física nos proporcionou algo distinto de um mero conhecimento de fatos, e que ela nos levou a descobrir as relações reais das coisas umas com as outras. (DUHEM, 1974, p. 328).

Essa tensão reflete o fato de que Poincaré não dispõe de um sistema apropriado de valores epistemológicos, fins e normas metodológicas, como também de princípios para dar conta racionalmente do processo da teorização científica. Como resultado dessa ausência de recursos de análise, verifica-se claramente um caráter artificial da unidade entre os valores objetivo e prático da teoria física proposta pelo pragmatismo (DUHEM,1974, p. 328). Não há consistência entre os seus recursos metodológicos que levam ao valor prático da teoria física e seu instinto e intuição que pedem uma organização unitária da física, e mesmo um valor objetivo.

Finalmente, pode-se interpretar o pragmatismo como uma mudança epistemológica ad hoc com relação à visão empirista/indutivista da física, ao invés de considerá-lo como uma reformulação própria do método científico, mais compatível com uma física verdadeiramente matemática, uma vez que a concepção pragmatista/convencionalista contemporânea incorpora a visão do empirismo clássico e uma série de suas teses, exceto por certas inovações, tais como a rejeição de experimentos cruciais e a introdução de convenções na física teórica. 


\section{III - O SUBPROGRAMA NEOCLÁSSICO DO REALISMO CONVERGENTISTA ESTRUTURAL DE DUHEM}

A teoria da ciência de Duhem, concebida como uma filosofia sistemática, conceitualmente bem articulada, contrasta nitidamente com o método nãosistemático do pragmatismo/empirismo empregado na análise crítica das teorias científicas. A abordagem não-sistemática, fragmentada, do procedimento metodológico de Poincaré é a raiz da crítica duhemiana das inconsistências e do caráter ilógico da pesquisa pragmatista/positivista na ciência.

Em resumo, Duhem alega que a concepção pragmatista/empirista da teoria física (a) não dispõe da maquinaria metodológica articulada e necessária para proporcionar uma solução racional do problema da combinação dos valores prático e objetivo da teoria física, e em particular para descrever o progresso racional e contínuo da ciência. Ela possui uma metodologia inadequada e exageradamente simplificada e fragmentada, para elaborar uma descrição racional da física, com o agravante de ser uma metodologia (tendo rejeitado, de modo não crítico, a metafísica) que se encontra reduzida a uma crítica puramente lógica da ciência. É justamente esse método incompleto, não-sistemático, fragmentado e gradativo de abordagem da teorização científica que se revela insuficiente para proporcionar uma descrição racional dos problemas fundamentais de uma teoria da ciência. Além disso, (b) essa concepção, a partir da aplicação do princípio da subdeterminação da teoria pelos dados (PSTD), gera o ceticismo.

A principal estratégia de Duhem para se opor a essa concepção convencionalista/pragmatista é a formulação de uma teoria da dinâmica do crescimento do conhecimento, na busca da realização de uma teoria ideal que representa uma classificação natural das leis físicas. A concepção de teoria física dessa teoria dinâmica é concebida como uma alternativa intermediária (middle way) a uma concepção metafísica (no sentido de fundamento) e a uma concepção pragmatista/indutivista/empirista da teoria física e de seu crescimento.

Duhem desenvolve sua reflexão, contrariamente ao modo de reflexão dos convencionalistas/pragmatistas, sobre a teoria física como um sistema de objetivos, teses, valores, normas e padrões que transcendem a lógica e o método empírico, para construir meios racionais e objetivos que permitam a apreciação e a avaliação crítica da teoria física.

A metodologia da demarcação de Duhem com respeito à concepção metafísica da ciência, no sentido fundacionalista de Descartes, segue a estratégia de redefinir a noção de teoria física como física matemática, retirando dela os objetivos de busca pelas causa reais do fenômenos e atendo-se à ideia da 
introdução de ordem e classificação entre as leis empíricas. Duhem explica da seguinte forma sua proposta para a natureza da teoria física:

[A teoria física] é um sistema de proposições matemáticas, deduzidas de um pequeno número de princípios que buscam representar, de maneira tão simples, completa e exata quanto possível, um conjunto de leis experimentais. (DUHEM,1974, p. 19).

Essa definição de teoria física como um sistema que tem por objeto a representação das leis empíricas se baseia na ideia de representação como uma relação simbólica entre conceitos físicos e propriedades físicas e no uso da álgebra como a linguagem apropriada para expressar e manipular tais símbolos. Essa definição salienta o caráter representacional, e não o explicativo (tal como proposto pelo mecanicismo), como a propriedade essencial da teoria científica. Ela ressalta que a teoria física busca a classificação e a organização das leis empíricas, e não explicações causais. Já a concepção metafísica define que a natureza da física teórica proporciona semelhantes explicações. Desse modo, o distanciamento de Duhem da tradição metafísica é estabelecido já na definição da teoria física.

A metodologia de Duhem desenvolve um método para construir a teoria física a partir dessa definição: o método abstrato (DUHEM, 1974, p.78). Esse método substitui o método sintético de construção de modelos mecânicos de Descartes e os estratagemas dos modelos de massas invisíveis em movimento de Poincaré, aproximando-se do método para construção de teorias físicas, como o da termodinâmica.

Quatro pontos devem ser observados. (1) O fato de que o caráter mesmo da teoria física é a representação significa que esta é um sistema de símbolos linguísticos e que não há qualquer relação de natureza entre o signo e as coisas significadas. (2) A linguagem própria para representar as propriedades físicas é a matemática e a linguagem matemática apropriada é a álgebra. (3) A natureza da teoria física como representação é uma consequência automática de uma análise lógica estrita da mesma. (4) O método para construir semelhante definição de teoria física proporciona um tipo de definição operacional. Esse aspecto, embora não tenha sido notado, é fundamental para a definição de teoria física. Tal definição não se pretende nem especulativa nem vaga, mas funcional e operacional, isto é, derivada de um conjunto de regras específicas e determinadas, designadas para produzir teorias físicas particulares, de maneira efetiva (DUHEM, 1974, p.20). Esse aspecto operacional supostamente oferece os meios para evitar a introdução de indeterminações e modelos mecânicos em física e também para demarcá-la da metafísica. 
A operacionalização da demarcação com relação à metafísica é realizada pelo procedimento de como construir teorias físicas. O meio para evitar a metafísica é o controle na construção da teoria física. Esse método consiste em (i) uma teoria da formação de conceitos; (ii) critérios para escolher os conceitos primitivos; (iii) critérios e restrições metodológicas para a seleção das hipóteses das teorias; (iv) a adoção da análise lógica - que é um dos dois componentes do método histórico-crítico de Duhem - como o instrumento analítico apropriado, junto com a teoria da mensuração, a fim de construir a física teórica como representação e não explicação.

A teoria da formação dos conceitos estabelece as exigências que os conceitos devem satisfazer, para serem aceitos como conceitos da física teórica. $\mathrm{O}$ instrumento metodológico fundamental dessa teoria da formação dos conceitos é a teoria da mensuração. Esse instrumento garantirá a condição de que a física teórica deve ser uma teoria matemática. Ele garantirá as condições para aceitar em física teórica, conceitos capazes de serem associados com números. Este é seu importante instrumento metodológico para minimizar as indeterminações na teoria física. Apenas definições e conceitos bem estabelecidos devem ser usados em teorias físicas. O que vem a ser definições e conceitos bem estabelecidos deve ser decidido com a ajuda de (a) uma teoria da mensuração; (b) critérios para escolher conceitos primitivos (guias metodológicos para a seleção de conceitos primitivos); (c) critérios e restrições metodológicas para a seleção de pressuposições/hipóteses básicas.

A aplicação consistente e rigorosa desse método abstrato deve fazer da física teórica um sistema verdadeiramente racional, como enfatiza Duhem: “[... a physical theory will then be a system of logically linked propositions and not an incoherent series of mechanical or algebraic models" (DUHEM, 1974, p. 107).

Se, por um lado, o método abstrato operacionaliza a demarcação entre física e metafísica, não se pode esquecer, por outro lado, que a concepção de Duhem é oposta à concepção pragmatista/empirista. Essa oposição também é expressa claramente em sua teoria da formação dos conceitos. Sua visão dos termos teóricos em física teórica, da relação entre teoria e experimento, do problema das teorias equivalentes e do problema da escolha de hipóteses marca claramente sua diferença da concepção pragmatista/empirista.

Para ele, esses assuntos vão além de uma análise puramente lógica da física teórica. E é precisamente esse aspecto - expresso implicitamente em algumas de suas teses epistemológicas, ontológicas e axiológicas - que o diferencia de seus contemporâneos, em particular de Poincaré e mesmo de Mach, que está comprometido com uma concepção pragmatista/empirista mais radical. Pode- 
se ver igualmente que sua teoria da formação de conceitos é mais próxima das concepções mais recentes de Carnap e Hempel sobre o assunto, enquanto os pragmatistas/empiristas são mais próximos das primeiras concepções destes.

Uma conclusão imediata dessa demarcação é que agora há incomensurabilidade entre a teoria física e a metafísica (DUHEM, 1893a), por haver incomensurabilidade entre as proposições pertencentes à primeira e aquelas pertencentes à segunda. Como Duhem afirma,

[...] não pode haver acordo ou desacordo entre uma proposição acerca de uma realidade objetiva e outra proposição que não possui qualquer relevância objetiva. Sempre que as pessoas citam um princípio da física teórica em defesa de uma doutrina metafísica ou de um dogma religioso, cometem um engano, pois atribuem a este princípio um significado que não é lhe próprio, uma relevância que não lhe pertence. (DUHEM, 1974, p. 287).

O segundo ponto da definição é que a interpretação padrão da proposta de Duhem compreende esta última como o paradigma de uma concepção convencionalista/instrumentalista/pragmatista (CARTWRIGHT, 1983, p. 7677, 87-99; VAN FRAASSEN, 1980, p. 2, 34-36, 86; GIEDYMIN 1982). Com respeito a essa definição de teoria física, Mary Hesse afirma que "[...] a definição mesma de Duhem de teoria física, apresentada no início do livro, é a quintessência do instrumentalismo" (HESSE 1980, p. 208). John Worrall também tece os mesmos comentários a respeito dessa definição, bem como da de Poincaré: "Tanto Duhem como Poincaré eram definitivamente instrumentalistas nos meus termos" (WORRALL, 1982, p. 203)5.

Não há, contudo, qualquer surpresa a propósito dessa interpretação instrumentalista/convencionalista da definição apresentada por Duhem da natureza da teoria física: tal definição não é diferente daquelas formuladas por seus contemporâneos pragmatistas, a exemplo de Mach e Poincaré, como vimos acima (MACH, 1960, p. 586-595; 1986; POINCARÉ, 1952; 1902), ou Le Roy (LE ROY, 1899, p. 526-534). Afinal, o objetivo deles é o mesmo: demarcar-se da metafísica.

Consequentemente, com relação à estratégia para realizar o objetivo de demarcar a teoria física da concepção metafísica, Duhem toma partido com a maioria de seus contemporâneos que se opõem à abordagem metafísica da teoria física. As concepções de Duhem e de Poincaré acerca do objetivo da teoria física são subdeterminadas com respeito à tarefa de demarcar física e metafísica. Ambas as concepções definem a natureza da teoria física, de modo a realizar semelhante demarcação.

\footnotetext{
5 Worrall reavalia, entretanto, a interpretação instrumentalista que Popper apresenta de Duhem. 
Nossa tese se opõe radicalmente à interpretação-padrão de Duhem como um instrumentalista/convencionalista. A comparação de Duhem com Poincaré, a definição de teoria física de Duhem e sua intenção de demarcar esta última da metafísica não autorizam a conclusão de que ele desenvolve também uma concepção convencionalista/pragmatista/instrumentalista da ciência. Ao contrário, a principal preocupação da teoria da ciência de Duhem é exatamente evitar esta última concepção da ciência.

É em virtude, segundo nossa hipótese, de sua teoria da ciência que Duhem se separa de outros teóricos da ciência, particularmente dos convencionalistas/ pragmatistas. Sem o conjunto de compromissos expressos por tal teoria, a racionalidade da empresa científica seria reduzida às meras intuições do físico enquanto físico e a descrição racional do progresso científico tornar-se-ia impossível. O progresso científico pareceria então um acidente. Por essa razão, é através da reconstrução e análise do significado desses compromissos, que pretendemos reconstruir em sua teoria da ciência, que Duhem busca uma concepção filosófica incompatível com uma interpretação instrumentalista/convencionalista da teoria física. Sua concepção de teoria física não é apenas diferente da interpretação usual que a reduz à concepção pragmatista/convencionalista, mas se desenvolve fundamentalmente em oposição a essa escola e, em particular (de acordo com o próprio Duhem), contra a visão pragmatista de Poincaré.

No intuito de demarcar-se dos convencionalistas/pragmatistas, Duhem desenvolve um conjunto de teses ontológicas, epistemológicas e axiológicas que formam uma moldura metafísica que estabelece as condições e restrições para elaborar sua teoria da dinâmica do desenvolvimento científico contínuo e racional. Duhem rejeita a ideia do sujeito transcendental do racionalismo clássico, que estava equipado epistemologicamente para ter acesso direto às essências do mundo. Ele substitui o sujeito transcendental por um sujeito falível submetido à tese empirista do conhecimento. Todavia, se, por um lado, ele rejeita o sujeito transcendental do conhecimento e, portanto a possibilidade do acesso direto ao conhecimento certo, por outro lado, Duhem formula uma tese ontológica que afirma a existência de uma teoria transcendental, uma teoria ideal, que descreveria uma classificação natural das leis da física.

Esses dois componentes de sua estrutura metafísica formam o ponto de partida do conhecimento - conhecimento hipotético, pois o sujeito é falível e o ponto de chegada - a teoria ideal que representa uma classificação natural das leis da física. Como ir de um estado de conhecimento (hipotético) a outro (conhecimento certo)? Por meio de uma trajetória que se realiza no tempo e que deve ser traçada e conduzida pela teoria da dinâmica do crescimento científico. Assim, a teoria da dinâmica é uma teoria normativa capaz de elaborar comandos 
e regras metodológicas com a finalidade de conduzir os cientistas, na elaboração das teorias científicas, à realização da teoria ideal. Esses traços gerais da ideia de Duhem de como transformar as teorias científicas, como conhecimento hipotético, em conhecimento certo, a qual se daria com a realização da teoria ideal, são elaborados por um cientista que, tendo pleno conhecimento do estado de conhecimento da época, utiliza os novos modelos científicos para explorá-los heuristicamente, no forjamento de instrumentos capazes de resolver problemas de ordem epistemológica.

O problema que se coloca é quanto à possibilidade do conhecimento objetivo e certo, dado que o indivíduo é falível. Duhem constrói essa solução quanto à possibilidade do conhecimento certo a partir do conhecimento hipotético (compatível com a ideia de que o sujeito do conhecimento é falível) mediante a teoria dinâmica do crescimento científico. A solução é encontrar uma trajetória do desenvolvimento científico que evolua para um estado do conhecimento representado pela teoria ideal. O modelo dessa proposta são as soluções de equações diferenciais, entre elas a solução de equilíbrio, e as soluções como trajetórias que evoluem para essa solução de equilíbrio. No caso de Duhem, essa proposta de uma teoria dinâmica é uma proposta normativa. A sua teoria deverá propor a trajetória a seguir e deverá criar regras e comandos, a fim de determinar a conduta dos cientistas na busca do que ele entende por teoria ideal como classificação natural das leis empíricas.

O segundo elemento dessa teoria é o compromisso com a tese racionalista de que o princípio fundamental da teoria física é o princípio da unidade lógica (PUL). Esse compromisso racionalista é um componente fundamental, na elaboração da teoria dinâmica. Com esse compromisso, ele quer evitar as indeterminações que são introduzidas pela adoção do princípio da subdeterminação da teoria pelos dados. Dessa forma, Duhem escolhe, entre os dois princípios, aquele que aumenta a possibilidade do sucesso da teoria dinâmica na realização do seu fim, que é a teoria ideal. O princípio da unidade lógica é um princípio do racionalismo clássico e pertence ao núcleo duro da racionalidade.

Um aspecto importante do racionalismo neoclássico é que sua construção está claramente associada à ciência do século XIX, que não mais comportava os pressupostos do racionalismo clássico e exigia uma reformulação de suas bases epistemológicas, axiológicas e ontológicas. Por essa razão, atribuímos à complexidade da ciência do século XIX o aparecimento de duas concepções epistemológicas da teoria física influenciadas pela interpretação que deram a essa complexidade: a concepção de Duhem e a de Poincaré. 
A emergência de várias áreas autônomas da física, como termodinâmica e eletromagnetismo, colocaram em xeque a capacidade unificadora da mecânica interpretada como construção de modelos mecânicos. A ascensão e queda de teorias, como, por exemplo, a teoria do calórico, colocaram em questionamento o sujeito transcendental e sua capacidade de acesso às essências e elegeram o sujeito falível com acesso direto às observações empíricas como seu princípio epistemológico (CHIAPPIN, 1989). As dificuldades de interpretação dos testes experimentais, por exemplo, sobre a teoria da luz, colocaram em questão as teses epistemológicas clássicas do método experimental.

Poincaré manteve o princípio da separabilidade e testabilidade isolada das hipóteses e introduziu estratagemas convencionalistas que consistem na construção de modelos de massas invisíveis e movimentos, para mostrar a impossibilidade de se usar o método experimental como método de prova. Poincaré rejeitou, desse modo, a possibilidade de que a experiência decida conclusivamente pelo valor de verdade das hipóteses.

Duhem rejeitou esses dois princípios clássicos. Todavia, ele substituiu o primeiro pela tese $\mathrm{D}$, que afirma que apenas a teoria física como um todo pode ser passível de teste e não suas hipóteses. Ele presumiu que o método experimental não pode decidir conclusivamente pela verdade da teoria, mas pode decidir conclusivamente por sua refutação. A razão dessa separação metodológica é que, na interpretação de Duhem, o processo de teste envolve duas teorias e a natureza. Ele introduz, por conseguinte, um sistema complexo para analisar o processo de teste que pressupõe dois momentos metodológicos: de um lado, refutação e rejeição, e, do outro, um método de escolha racional com elementos extralógicos para operar essa dicotomia metodológica e selecionar a melhor teoria. Além disso, Duhem introduziu o princípio de que não existem fatos brutos, mas fatos impregnados de teoria. Portanto, não há uma separação entre base empírica e teoria. Duhem extrai da natureza da física teórica como estrutura representacional essa ideia dos fatos impregnados de teorias:

Um experimento em física é a observação precisa dos fenômenos
acompanhada por uma interpretação dos mesmos; esta interpretação substitui os
dados concretos realmente obtidos através da observação por representações
abstratas e simbólicas que lhes correspondem em virtude das teorias admitidas
pelo observador. (DUHEM, 1974, p. 174).

Porém, o mais extraordinário dessa conexão entre ciência e filosofia vem da emergência de novos instrumentos matemáticos e das diferentes interpretações que foram atribuídas a eles por esses dois excepcionais cientistas e também 
filósofos. Talvez sejam essas interpretações que deram origem às diferentes concepções da teoria física desenvolvidas por esses autores.

No final do século, emergiram novos sistemas que apresentaram a propriedade da dependência hipersensível das condições iniciais. Essa sensibilidade às condições iniciais torna a previsibilidade do futuro muito difícil. Trajetórias que têm suas origens muito próximas podem afastar-se completamente, ao evoluir no tempo. Pequenas causas produzem grandes efeitos. Hadamard foi um matemático que, no final do século XIX, inventou um desses sistemas que tinha essa propriedade. O físico David Ruele assim se refere a essa invenção:

O sistema considerado por Hadamard é uma espécie de bilhar retorcido, em
que a superfície plana da mesa é substituída por uma superfície de curvatura
negativa. Ele se interessa pelo movimento de um ponto ligado à superfície
sobre a qual esse ponto se desloca sem atrito. O bilhar de Hadamard é,
portanto, o que chamamos em termos técnicos, o fluxo geodésico sobre uma
superfície de curvatura negativa. Esse fluxo geodésico é muito fácil de se
analisar matematicamente, o que permitiu Hadamard provasse o teorema da
dependência hipersensível das condições iniciais. (RUELE, 1993).

Poincaré estava ciente de que certos sistemas possuíam tais propriedades, uma vez que ele mesmo foi quem descobriu essas propriedades em alguns sistemas e tornou-se o inventor dos sistemas dinâmicos. Ele explora essa estranha propriedade do sistema de ser ao mesmo tempo determinado, pois regulado por equação, e imprevisível. Outra maneira de expressar isso era o sistema determinístico, no qual o acaso era possível. Assim o autor se expressa:

\footnotetext{
Uma causa muito pequena, que nos escapa, determina um efeito considerável que não podemos deixar de ver, e, então, dizemos que esse efeito se deve ao acaso (POINCARÉ, 1908, capítulo 4).
}

Como Poincaré criou a teoria dos sistemas dinâmicos, ele certamente teve a possibilidade de encontrar sistemas com vários estados de equilíbrio, nos quais não se poderia prever quais seriam as trajetórias escolhidas, devido às condições iniciais de hipersensibilidade, nem para qual estado de equilíbrio elas acabariam indo. O sistema comporta determinismo e imprevisibilidade.

Esse fator de indeterminação proveniente das características dos sistemas dinâmicos caóticos e a indeterminação trazida pela mecânica analítica (se podemos construir um modelo mecânico, podemos construir infinitos, para a mesma base empírica) oferecem fortes subsídios para a escolha de Poincaré de uma concepção convencionalista/pragmatista sustentada metodologicamente pelo princípio da subdeterminação da teoria pelos dados e pela crença de que não há experimentos 
conclusivos em física. A implicação epistemológica disso é que a teoria física só possui um valor prático e instrumental, sem qualquer adesão a um valor de conhecimento. Poincaré pondera com mais força os resultados da teoria física do que seus princípios filosóficos e, ao contrário, elabora os princípios filosóficos a partir de sua prática científica.

Nesse contexto, Poincaré aceita a pluralidade das diversas áreas da física, como eletromagnetismo, mecânica e termodinâmica, inclusive valorizando-a em seu aspecto heurístico, a ponto de dizer que não se furtaria a utilizar teorias contraditórias, conforme o princípio da subdeterminação da teoria pelos dados, desde que o uso das mesmas facilitasse o entendimento das propriedades físicas dos fenômenos. Nesse sentido, essa concepção de ciência convencionalista/ pragmatista, nos seus contornos epistemológicos, ontológicos, axiológicos e metodológicos, é bastante consistente com o desenvolvimento trazido por Poincaré com seus estudos sobre a teoria dos sistemas dinâmicos, em particular da teoria do caos, que envolve determinismo com imprevisibilidade.

Duhem, ao contrário, parece estar comprometido com um núcleo duro de valores e princípios que são capazes de moldar as características de seu fazer científico e da elaboração de sua imagem da ciência. Em particular, seu compromisso racionalista parece ser hierarquicamente um princípio constitucional de sua concepção de teoria física. Esse compromisso racional operacionaliza-se pela adesão ao princípio da unidade lógica e pela construção de critérios e regras para proporcionar decisões.

Nessa moldura de princípios e valores, ele constrói uma teoria normativa do desenvolvimento científico. Trata-se de uma teoria normativa, pois ela tem pretensões de orientar o comportamento dos cientistas, dizendo como construir uma teoria física com objetivos de representação das leis físicas Esse caráter normativo da teoria da ciência de Duhem (CHIAPPIN, 1989) fica bem claro quanto ao uso de sistemas dinâmicos em física e aos novos instrumentos matemáticos de Hadamard, que são os fluxos geodésicos.

O princípio da racionalidade é tão forte que, em nome dele, Duhem rejeita o trabalho de Hadamard, por acreditar que se trata de um instrumento inútil em física, uma vez que, embora se trate de um sistema determinístico, ele não permite a previsibilidade. Em física, somente poderemos utilizar instrumentos que gozam, por exemplo, da propriedade da continuidade, no sentido de que as equações levam de vizinhanças em vizinhanças. E esse não é o caso da teoria dos sistemas dinâmicos caóticos, os quais têm a propriedade de serem hipersensíveis às condições iniciais. 
Para evitar esse tipo de indeterminação e fugir das consequências epistemológicas da concepção de Poincaré, Duhem formula as seguintes condições que um instrumento matemático deve obedecer, para ser aplicado em física: (1) ele deve provar que uma proposição derivada permaneça aproximadamente exata, quando a primeira é apenas aproximadamente verdadeira; e (2) ele deve mostrar que o domínio dessas duas aproximações é delimitado. É necessário fixar o limite de erro admitido no resultado, quando o grau de precisão dos métodos de medição dos dados é conhecido, bem como o erro provável que pode ser aceito, quando desejamos conhecer o resultado no interior de um grau definido de aproximação (DUHEM, 1974, p. 143).

Duhem cita as geodésicas de superfícies de curvatura negativa de Hadamard, com múltiplas conexões e infinitas concavidades, como um exemplo de instrumento matemático a ser evitado (DUHEM, 1974, p. 139). É possível haver uma situação na qual tenhamos teorias distintas construídas logicamente, que concordem com os mesmos resultados empíricos. Nesse caso, tal como Poincaré, deve-se tratá-las como equivalentes? De modo algum, afirma Duhem. Como vimos, ele situa a racionalidade das decisões para além de uma simples adequação empírica e lógica.

O desdobramento desse racionalismo de Duhem, comprometido com o princípio da unidade lógica, é defender a unificação da física, agora não mais pela mecânica com suas indeterminações, mas pela termodinâmica, que é, para ele, o paradigma de uma teoria física matemática representacionista. A termodinâmica de Duhem é a termodinâmica de Gibbs (DUHEM, 1886), com suas funções e representações da energia e entropia e seus princípios associados de mínimo e de máximo. E, principalmente, a possibilidade, por meio de um algoritmo, de construir essas funções a partir das leis empíricas da termodinâmica, construção na qual tem papel decisivo a relação Duhem-Gibbs (CALLEN, 1985).

CHIAPPIN; J. R. N.; LEISTER; A. C. A rational reconstruction of the research program of neoclassical rationalism: the subprogrammes of conventionalism/pragmatism (Poincaré) and of convergent structural realism (Duhem). Trans/Form/Ação, Marília, v. 34, n.2, p. 103-134, 2011.

ABSTRACT: The aim of this article é to propose a rational reconstruction of a research program of the neoclassical rationalism as a replacement for the program of the classical rationalism. The neoclassical program has as his main objective the construction of a new conception of science 
CHIAPPIN; J. R. N.; LEISTER; A. C.

as representation instead of explanation. It is made of three subprograms: the conventionalism/ pragmatism of Poincaré, the structural realism of Duhem and the logical empirism.

KEYWORDS: Conventionalism. Convergent Realism. Neoclassical rationalism.

\section{REFERÊNCIAS}

BACON, F. Novum Organum, Of true directions concerning the Interpretation of nature. Illinois: Open Court Publishing Company, New Edition. 1994. BACON, F. Novum Organum. São Paulo: Abril, 1984.

CALLEN, H. Thermodynamics and an Introduction to Thermostatistics. New York: John Willey and Sons. 1985.

CARTWRIGHT, N. How the laws of physics lie. New York: Clarendon Press, 1984.

CHIAPPIN, J.R.N. Duhem's Theory of Science: An Interplay between Philosophy and History of Science. Ph.D thesis. Pittsburgh: University of Pittsburgh. 1989.

CHIAPPIN, J.R.N. Racionalidade, Decisão, Solução de Problemas e o Programa Racionalista. Ciência e Filosofia. Volume 5, 1996.

CHIAPPIN, J.R.N. Reconstrução Racional da concepção popperiana da ciência:o racionalismo crítico como termo médio entre o dogmatismo e o relativismo. Khronos. Número 1. 2008.

CHIAPPIN, J.R.N.; LEISTER, A. C. A reconstrução racional do programa de pesquisa do racionalismo clássico sob a perspectiva da abordagem de solução de problemas. Revista Discurso. Número 39, 2009.

CHIAPPIN, J.R.N.; LEISTER, A. C. A reconstrução racional do programa de pesquisa sobre o racionalismo clássico: Locke e a vertente empirista. Filosofia Unisinos. Volume 10. Número 2, maio/agosto 2009.

DESCARTES, R. OEuvres philosophiques.Tome I. Edition de F. Alquié. Paris : Éditions Garnier Frères, 1963.

DESCARTES, R. OEuvres philosophiques.Tome II. Edition de F. Alquié. Paris : Éditions Garnier Frères, 1967.

DESCARTES, R. OEuvres philosophiques. Tome III. Edition de F. Alquié. Paris : Éditions Garnier Frères, 1971.

DUGAS, R. A History of Mechanics. New York: Dover Publications, INC., 1988.

DUHEM, P. Le potentiel thermodynamique et ses applications à la mécanique chimnique et à l'étude des phénomenes électriques. Paris: A. Hermann, 1886.

DUHEM, P. Physique et Métaphysique. Revue des Questions Scientifiques. 34 : 55-83, 1893 a. 
DUHEM, P. L'École Anglaise et Les Théories Physiques, à propos d'un livre de W. Thompson. Revue des Questions Scientifiques. 34: 345-378, 1893b.

DUHEM, P. Fragments d'un cours d'optique - Deuxième fragment : Coup d'œil sur l'optique ancienne. L'optique de Young. Annales de la Société Scientifique de Bruxelles XIX : 27-94, 1895.

DUHEM, P. Théorie et pratique. Revue Philomathique de Bordeaux et du Sud-Ouest : 250-262, 1900.

DUHEM, P. The Aim and Structure of Physical Theory. New York: Atheneum Press, 1934.

GIEDYMIN, J. Science and convention : essays on Henri Poincaré's philosophy of science and the conventionalist tradition. New York: Pergamon Press, 1982.

GRUNBAUM, A. Is it never possibly to falsify a hypothesis irrevocably ? In: HARING, S.G. (Ed.). Can theories be refuted? Dordrecht: D. Reidel Publishing., 1976.

HESSE, M. Duhem, Quine and a New Empiricism. In Harold Morick (Ed.).). Challenges to Empiricism. Indianapolis: Hackett Publishing Company. 1980.

HUME, D. Investigação sobre o entendimento humano. São Paulo: Abril. 1973.

HUME, D. A treatise of Human Nature. With notes by P. H. Nidditch. Oxford: Clarendon Press, 1980.

KANT, E. Prolegômenos a toda metafísica futura. São Paulo: Abril. 1974.

LAKATO, I. O falseamento e a Metodologia dos Programas de Pesquisa Científica. In: LAKATOS, I.; MUSGRAVE, A. (Org.). A Crítica e o Desenvolvimento do Conbecimento. São Paulo: Cultrix/Editora Universidade de São Paulo, 1979.

LAKATOS, I. Falsification and the Methodology of Scientific Research Programmes. In: WORRAL, J.; CURRIE, G. (Ed.). The methodology of scientific research programmes. Vol. 1. Cambridge: Cambridge University Press, 1984.

LANCZOS, C. The variational principles of mechanics. New York: Dover Publications, Inc., 1970.

LATSIS, SPIRO J. A research programme in economics. In: SPIRO, J. L. (Ed.). Method and Appraisal in Economics. Cambridge: Cambridge University Press, 1976.

LE ROY, E. Scicence et Philosophie. Revue de Metaphysique et le Morale 7: 503-562, 1899.

LOCKE, J. Ensaios acerca do Entendimento Humano. São Paulo: Abril. 1973.

LOCKE, J. An Essay concerning Human Understanding. Oxford: Clarendon Press Oxford, [1985].

MACH, E. Science on Mechanics: A critical and historical account. La Salle: The Open Court Publishing, 1960.

$\mathrm{MACH}, \mathrm{E}$. Principles of the theory of heat historically and critically elucidated. Dordrechet: D. Reidel Publishing, 1986.

NEWTON, I. Opticks. London: Dover Publications, 1952. 
CHIAPPIN; J. R. N.; LEISTER; A. C.

PARETO, V. Manuel d'Économie Politique. Paris: V. Riard et E. Briere, 1909.

POINCARÉ, H. Sur l'éxpérience de M. Wiener. Comptes Rendus CXII: 325-329, 1891.

POINCARÉ, H. Életricite e Optique: La Lumière et les théories electrodynamiques. Leçons professées à La Sorbonne em 1888 et 1899. Paris: Gauthier-Villars, 1901.

POINCARÉ, H. La Science et L'hipothèse. Paris: E. Flammarion, 1902.

POINCARÉ, H. Science and Method. New York: Dover Publications 1952.

POPPER, K. R. A Lógica da Pesquisa Cientifica. São Paulo: Editora Universidade de São Paulo/Cultrix, 1972.

POPPER, K. R. Realism and the Aim of Science. New Jersey: Rowan and Littlefield, [1983].

PUTNAM, H. Reason, Truth and History. Cambridge: Cambridge University Press, [1981].

REY, AB. La Philosophie Scientifique de M. Duhem. Revue de Metaphysique et Le Morale 12: 699-744, 1904.

RUELLE, D. Acaso e Caos. São Paulo: UNESP, 1993.

SILVA, C. C. A teoria das Cores de Newton: um exemplo do uso da história da ciência em sala de aula. Ciência e Educação. V. 9 n.1 p. 53-65, 2003.

SILVA, C. C.; MARTINS, R. A. A nova teoria das cores de Isaac Newton: uma tradução comentada. Revista Brasileira de Ensino de Física, v. 18 p. 313-217, 1996.

VAN FRAASSEN, B. The Scientific Image. New York: Oxford University Press, 1980.

VARIAN, H. R. Microeconomia. Princípios Básicos. Rio de Janeiro: Elsevier, 2006.

VICAIRE, E. De La Valeur Objective des Hypothèses Physiques. À Propôs d’un article de M. P. Duhem. Revue des Questions Scientifiques 31:451-510, 1892.

WORRAL, J. Scientific Realism and Scientific Change. Philosophical Quartely. 32: 201-231, 1982.

Recebido em: 7 de janeiro de 2011

Aprovado em: 2 de março de 2011 